\title{
Price or Quantity in Tacit Collusion?*
}

\author{
Luca Lambertini ${ }^{\dagger}$ and Christian Schultz ${ }^{\ddagger}$
}

October 2001

\begin{abstract}
We investigate the choice of market variable, price or quantity, of an optimal implicit cartel. If the discount factor is high, the cartel can realize the monopoly profit in both cases. Otherwise, it is optimal for the cartel to rely on quantities in the collusive phase if goods are substitutes and prices if goods are complements. The reason is that this minimizes the gains from deviations from collusive play.

KEYWORDS: partial collusion, product differentiation

JEL Classification Codes: D43, L13
\end{abstract}

\section{Introduction}

A recurrent theme in industrial organization is whether firms choose quantities or prices. Singh and Vives (1984) give a theoretical answer. They consider a differentiated duopoly where firms can choose whether to use prices or quantities and they show that firms choose quantities when goods are substitutes and prices when goods are complements. We investigate whether an implicit cartel, relying on tacit collusion, will choose quantities or prices. For very high discount factors, this does not matter, the monopoly profit can be realized in both cases. For lower discount factors this is not so, an optimizing cartel will choose quantities if goods are substitutes and prices if goods are complements. The reason is that these choices minimize the gains

*We thank Birgit Grodal, Per Baltzer Overgaard and seminar participants in Copenhagen and Bologna for very useful comments and discussion.

${ }^{\dagger}$ Department of Economics, University of Bologna, Strada Maggiore 45, I-40125 Bologna, Italy, fax: +390512092664, lamberti@spbo.unibo.it

${ }^{\ddagger}$ Centre for Industrial Economics, Institute of Economics, University of Copenhagen, Studiestraede 6, DK 1455 Copenhagen K, Denmark, fax: +4535323000, e-mail: Christian.Schultz@econ.ku.dk 
from deviation from collusive play. Contrary to the previous literature in this area, we assume that a firm commit to a price or a quantity for a period but cannot commit being a quantity (or price) setter forever.

Deneckere $(1983,1984)$ also studies a repeated duopoly. He calculates the smallest discount factor necessary for colluding on the monopoly profit if firms are committed to be price setters or quantity setters forever. This discount factor is smallest for quantities when goods are substitutes, and for prices when goods are complements. Deneckere interprets this as a cartel is more stable if it competes in quantities when goods are substitutes and in prices when goods are complements (see also Majerus, 1988; and Rothschild, 1992). Lambertini (1997) let firms non-cooperatively choose market variable once and for all in a meta-game before the repeated game. The payoff to the firms in the meta-game is not profit, but discount factors as those calculated by Deneckre. Firms are assumed to wish to minimize these discount factors. This leads to a prisoners dilemma structure, where firms choose the variables Deneckre found lead to less stable cartels.

Our paper improves on the literature in several aspects. Contrary to Lambertini, we insist that a firm's payoff is the total sum of discounted profits. There is no meta-game construction here. Secondly, we do not assume that firms can commit to a market variable for all future, the choice of market variable only commits the firm for one period. Thirdly, we cover the case where firms are unable to collude on monopoly profits and have to aim for lower collusive profits.

\section{The stage game}

The model is a symmetric, simplified, version of Singh and Vives (1984). There are two identical firms, producing differentiated goods, $i=1,2$ respectively. They are faced with inverse demand functions

$$
p_{i}=1-q_{i}-\gamma q_{j}
$$

where $q_{i}$ and $p_{i}$ are the quantity and price respectively of good of firm $i$ and $j \neq i$. Goods are substitutes if $0<\gamma<1$ and complements if $-1<\gamma<0$. Direct demands are

$$
q_{i}=\frac{1}{1+\gamma}-\frac{1}{1-\gamma^{2}} p_{i}+\frac{\gamma}{1-\gamma^{2}} p_{j}
$$

Marginal costs are normalized to zero. The per period profit of firm $i$ is $\pi_{i}=p_{i} q_{i}$. We allow for negative prices and quantities. Incorporating nonnegativity constraints would not change our results but complicate derivations. In the working paper version (Lambertini and Schultz, 2001) this is 
done. In each period there are two stages. In the first, each firm decides whether to set price or quantity in the period. In the second stage the actual value is chosen, this follows Singh and Vives (1984).

If both firms choose quantities firm 1's profit is

$$
\pi_{1}^{C}\left(q_{1}, q_{2}\right)=q_{1}-q_{1}^{2}-\gamma q_{2} q_{1}
$$

Given firm 2 has chosen $q$, the best reply quantity, $R C_{1}(q)$, for firm 1 solves $\max _{q_{1}} \pi_{1}\left(q_{1}, q\right)$, the associated profit is denoted $\pi_{1}^{D C}(q)$. Simple calculations yield

$$
R C_{1}(q)=\frac{1-\gamma q}{2} ; \text { and } \pi_{1}^{D C}(q)=\frac{(1-\gamma q)^{2}}{4}
$$

Whether firm 1 responds to a quantity chosen by firm 2 by choosing quantities or prices is irrelevant, in both cases firm 1 chooses the best point along the residual demand curve. Hence, when firm 2 sets a quantity, $\pi^{D C}(q)$ gives the best response profit to firm 1, regardless of whether it has chosen to set prices or quantities in the first stage.

The profit to each firm in the Cournot equilibrium is $\pi^{C N}=\frac{1}{(2+\gamma)^{2}}$. If they share the monopoly output, they each receive profit $\pi^{m}=\frac{1}{4(1+\gamma)}$. If both firms choose prices firm 1's profit is

$$
\pi_{1}^{B}\left(p_{1}, p_{2}\right)=\left(\frac{1}{1+\gamma}-\frac{p_{1}}{1-\gamma^{2}}+\frac{\gamma p_{2}}{1-\gamma^{2}}\right) p_{1}
$$

The best reply price, $R B_{1}(p)$, solves $\max _{p_{1}} \pi_{1}^{B}\left(p_{1}, p\right)$, the associated profit is $\pi_{1}^{D B}(p)$. Straightforward calculations give

$$
R B_{1}(p)=\frac{1-\gamma(1-p)}{2} \text { and } \pi_{1}^{D B}(p)=\frac{[1-\gamma(1-p)]^{2}}{4\left(1-\gamma^{2}\right)}
$$

The Bertrand equilibrium profit per firm is $\pi^{B N}=\frac{1-\gamma}{(2-\gamma)^{2}(1+\gamma)}$.

Singh and Vives (1984, proposition 2) show that the subgame perfect equilibrium of the two-stage game is unique. If $0<\gamma<1$, both firms to choose quantities, and the Cournot equilibrium results; if $-1<\gamma<0$, both firms to choose prices the Bertrand equilibrium results. 


\section{Best response profits}

We will consider symmetric equilibria. A given profit level can be obtained either by setting prices or quantities. In each case, we can calculate the best response profit associated with this level of prices or quantities and find out when the deviation profit is larger. Each firm obtains a profit $\pi$ if they both produce the quantity $q$ solving

$$
\pi=q-(1+\gamma) q^{2}
$$

This equation has two roots

$$
q=\frac{1+\sqrt{1-4(1+\gamma) \pi}}{2(1+\gamma)} \text { and } q=\frac{1-\sqrt{1-4(1+\gamma) \pi}}{2(1+\gamma)}
$$

We are interested in the root minimizing the best response profit, $\pi_{1}^{D C}(q)$. Tedious calculations show that for $\gamma>0$, this is the first (and larger) root, while for $\gamma<0$ it is the second root.

We therefore have

$$
\pi^{D C}(q(\pi))= \begin{cases}\frac{1}{4}\left(1-\gamma \frac{1+\sqrt{1-4(1+\gamma) \pi}}{2(1+\gamma)}\right)^{2} & \text { if } \gamma>0 \\ \frac{1}{4}\left(1-\gamma \frac{1-\sqrt{1-4(1+\gamma) \pi}}{2(1+\gamma)}\right)^{2} & \text { if } \gamma<0\end{cases}
$$

Now consider price setting. The price, $p$, which gives profit level $\pi$ solves

$$
\pi=\frac{1}{1+\gamma}\left(p-p^{2}\right) \text {. }
$$

Again there are two roots

$$
p=\frac{1-\sqrt{1-4(1+\gamma) \pi}}{2} \text { and } p=\frac{1+\sqrt{1-4(1+\gamma) \pi}}{2} .
$$

The first smaller root gives the smallest best response profit if $\gamma>0$, and the larger second root does if $\gamma<0$. Hence

$$
\pi^{D B}(p(\pi))=\left\{\begin{array}{l}
\frac{1}{4\left(1-\gamma^{2}\right)}\left[1-\gamma\left(1-\frac{1-\sqrt{1-4(1+\gamma) \pi}}{2}\right)\right]^{2} \text { if } \gamma>0 \\
\frac{1}{4\left(1-\gamma^{2}\right)}\left[1-\gamma\left(1-\frac{1+\sqrt{1-4(1+\gamma) \pi}}{2}\right)\right]^{2} \text { if } \gamma<0
\end{array}\right.
$$


For a given profit level $\pi$ we can now evaluate whether price- or quantitysetting give the highest associated best response profit. If goods are complements $-1<\gamma<0$, equations (7) and (10) yield

$$
\pi^{D C}(q(\pi))-\pi^{D B}(p(\pi))=\left(2 \pi \gamma+2 \pi \gamma^{2}-\gamma-\sqrt{(1-4 \pi-4 \pi \gamma)}\right) \frac{\gamma^{2}}{4\left(1-\gamma^{2}\right)(1+\gamma)}
$$

which has the same sign as the sign of the parenthesis. This is positive evaluated at the Bertrand profit $\pi^{B N}$ and it is increasing in $\pi$. Therefore we have

$$
\pi^{D C}(q(\pi))>\pi^{D B}(p(\pi)) \text { for }-1<\gamma<0 \text { and } \pi^{B N} \leq \pi \leq \pi^{m} .
$$

For $\gamma>0$ we have

$$
\pi^{D C}(q(\pi))-\pi^{D B}(p(\pi))=(2 \pi \gamma(1+\gamma)-\gamma+\sqrt{(1-4 \pi-4 \pi \gamma)}) \frac{\gamma^{2}}{4\left(1-\gamma^{2}\right)(1+\gamma)}
$$

which has the same sign as the sign of the parenthesis. This negative evaluated at the Cournot profit $\pi^{C N}$ and it is decreasing in $\pi$, hence we have that

$$
\pi^{D C}(q(\pi))<\pi^{D B}(p(\pi)) \text { for } 0<\gamma<1 \text { and } \pi^{C N} \leq \pi \leq \pi^{m} .
$$

\section{The repeated game}

The repeated game consists of the above market game repeated an infinite number of times. Firms maximize the sum of discounted profits and the common discount factor is $\delta$, where $0<\delta<1$. Discounting occurs between periods, but not between the two stages of a period. We follow Friedman (1971) and look for the best symmetric subgame perfect equilibrium for the firms, which can be sustained by trigger strategies where the punishment is reversion to the one shot (subgame perfect) Nash equilibrium. Whether firms use prices or quantities in the punishment phase depends on whether goods are substitutes or complements as follows directly from Singh and Vives (1984, proposition 2) cited above. Let $\pi^{N}$ be the profit of the subgame perfect equilibrium in the stage game.

As is well known, the non-deviation constraint in the normal phase stipulates that a firm should prefer its normal phase action to playing a best 
response and be punished in the future. When firms choose quantities the non-deviation constraint is

$$
\frac{1}{1-\delta} \pi \geq \pi^{D C}(q(\pi))+\frac{\delta}{1-\delta} \pi^{N}
$$

when they choose prices it is

$$
\frac{1}{1-\delta} \pi \geq \pi^{B C}(p(\pi))+\frac{\delta}{1-\delta} \pi^{N}
$$

The best sustainable profit is either the monopoly profit per firm, $\pi^{m}$, or the highest profit level $\pi<\pi^{m}$ for which the constraint is fulfilled with equality. The lowest discount factor, for which the monopoly profit can be sustained, makes the constraint fulfilled with equality. If firms set quantities, this discount factor is given as

$$
\delta^{Q} \equiv \frac{\pi^{D C}\left(q\left(\pi^{m}\right)\right)-\pi^{m}}{\pi^{D C}\left(q\left(\pi^{m}\right)\right)-\pi^{N}}
$$

(obviously, $\delta^{Q}$ depends on $\gamma$ ). If firms set prices the crucial discount factor, $\delta^{P}$, is given by the same expression where $\pi^{D B}\left(p\left(\pi^{m}\right)\right)$ is substituted for $\pi^{D C}\left(q\left(\pi^{m}\right)\right)$. It follows that the crucial discount factor is higher the higher the best response profit is. Using (11) and (12) we therefore have

$$
\begin{aligned}
& \delta^{Q}<\delta^{P} \text { if and only if } 0<\gamma<1 \\
& \delta^{Q}>\delta^{P} \text { if and only if }-1<\gamma<0
\end{aligned}
$$

If goods are substitutes $(0<\gamma<1)$, there is a range of discount factors, $\left[\delta^{Q}, \delta^{P}\right]$ where the monopoly profit can only be obtained by quantity setting. Here an implicit cartel will let the firms choose quantities. When goods are complements, the situation is reversed, and for some range firms choose prices. For very high discount factors, the choice of market variable is irrelevant.

If the discount factor is low the monopoly profit cannot be sustained. However, a cartel can at least ensure the minimum of the Bertrand and Cournot profit, so we can use (11) and (12). Suppose goods are substitutes, then $\pi^{D B}(p(\pi))>\pi^{D C}(q(\pi))$. Consider the profit level $\pi$, which makes (13) fulfilled with equality. At this level the inequality (14) is broken, $\pi$ can only be sustained by choosing quantities. We conclude, that if goods are substitutes, firms choose quantities. Similarly, if goods are complements they choose prices in the normal phase. To summarize the discussion

Theorem 1 There exist discount factors $\delta^{Q}$ and $\delta^{P}$, where $0<\delta^{Q}, \delta^{P}<1$ such that in the optimal trigger-strategy equilibrium with Nash-punishment. 
1. If $\delta>\max \left[\delta^{Q}, \delta^{P}\right]$, the choice of market variable is irrelevant. Firms obtain the monopoly profit.

2. If goods are substitutes $(0<\gamma<1)$, then $\delta^{Q}<\delta^{P}$. If $\delta<\delta^{P}$, firms set quantities in the normal phase. If $\delta \in\left[\delta^{Q}, \delta^{P}\right]$, firms obtain the monopoly profit; if $\delta<\delta^{Q}$, they obtain less.

3. If goods are complements $(-1<\gamma<0)$, then $\delta^{P}<\delta^{Q}$. If $\delta<\delta^{Q}$, firms set prices in the normal phase. If $\delta \in\left[\delta^{P}, \delta^{Q}\right]$ firms obtain the monopoly profit; if $\delta<\delta^{P}$, they obtain less.

The crucial element in the arguments above is that the size of the best response profit depends on which market variable the firms use. This is independent of the particular punishment phase. The punishment phase is important for the exact values of $\delta^{Q}$ and $\delta^{P}$, but not for arguments that a cartel will instruct firms to use quantities if goods are substitutes for lower discount factors and prices if goods are complements. These results are also valid for different (for instance optimal) punishment phases.

\section{$5 \quad$ References}

Deneckere, R. (1983), "Duopoly Supergames with Product Differentiation", Economics Letters, 11, 37-42.

Deneckere, R. (1984), "Corrigenda", Economics Letters, 15, 385-7.

Friedman, J.W. (1971), "A Noncooperative Equilibrium for Supergames", Review of Economic Studies, 38, 1-12.

Lambertini, L. (1997), "Prisoners' Dilemma in Duopoly (Super)Games", Journal of Economic Theory, 77, 181-91.

Lambertini, L. and C. Schultz (2001), "Price vs Quantity in a Repeated Differentiated Duopoly", downloadable at www.dse.unibo.it/lamberti/repeat2.pdf

Majerus, D. (1988), "Price vs Quantity Competition in Oligopoly Supergames", Economics Letters, 27, 293-7.

Rothschild, R. (1992), "On the Sustainability of Collusion in Differentiated Duopolies", Economics Letters, 40, 33-7.

Singh, N. and X. Vives (1984), "Price and Quantity Competition in a Differentiated Duopoly", RAND Journal of Economics, 15, 546-54. 